\title{
Anti-EGFR/DM1 Antibody-drug Conjugate AVID100
}

National Cancer Institute

\section{Source}

National Cancer Institute. Anti-EGFR/DM1 Antibody-drug Conjugate AVID100. NCI

Thesaurus. Code C148507.

\begin{abstract}
A targeted antibody drug conjug ate (ADC) consisting of a human monoclonal antibody directed against the epidermal growth factor receptor (EGFR) conjug ated to the cytotoxic agent maytansinoid mertansine (DM1), with potential antineoplastic activity. Upon intravenous administration, the monoclonal antibody moiety of AVID100 binds to and inhibits EGFR on tumor cell surfaces. Inhibition of EGFR prevents EGFR-mediated signaling and may inhibit tumor cell proliferation. Following receptor internalization, the mertansine moiety binds to tubulin and interferes with microtubule assembly/disassembly dynamics. This inhibits both cell division and proliferation of cancer cells that express EGFR. EGFR, overexpressed by a variety of cancers, plays a key role in tumor cell proliferation and survival.
\end{abstract}

